\title{
Über die Foramina acustica media an der Ohrkapsel von Reptilien.
}

\author{
Von \\ San'ichi Miyawaki. \\ Aus dem Anatomischen Institut der Keio Universität, Tokyo. \\ Mit 13 Textfiguren.
}

Autoren wie Stöhr ('80), Windischmann ('81), Retzius ('81), Okajima ('10) u.a. haben bestätigt, dass an der Ohrkapsel der Urodelen die Foramina acustica media drei bis mehrfach vertreten sind (Siredon, Triton, Megalobatrachus, Onychodactylus, Hynobius und Salamandra); auch ich ('26) fand neuerdings bei den japanischen Anuren, in allen untersuchten Fällen von Hyla arborea japonica, selten bei Rana japonica sowie Rana nigromaculata, deren drei.

Über das Gehörorgan der Reptilien hatten, ausgenommen von älteren Autoren, viele Forscher, wie Kuhn ('82), Retzius ('84), Osawa ('98), Gaupp ('00), Schauinsland ('00), Kunkel ('11), Nick ('12), Zimmerminn ('13), Shiino ('14), Rice ('20) a.a.m. bereits eingehend berichtet und nach ihnen ist das Vorhandensein der zwei Foramina acustica an der Ohrkapsel als die Norm betrachtet worden. Aber bei den neueren Untersuchungen wurden beim Reptilienohr drej oder mehr Hörlöcher gezählt. So fand Ogushi ('11) deren vier oder fünf bei Trionyx japonicus. Er sagt: "An der medialen Wand (der Ohrkapsel) bemerken wir vor allem, in der Reihe von vorn nach hinten, das Foramen acusticum anterius principale (im Bereiche des Recessus anterior) und 2 oder 3 Foramina acustica anteriora accessoria auf dem Gebiet des Prooticum, damn von oben nach unten gereiht 3 Löcher: das Foramellum vasi vestibuli, das Foramellum aqueductus endolymphatici und endlich das Foramen acusticum posterius." Nick ('12) gibt beim Dermochelys an, dass in der Umgebung des Foramen anterius n. acustici 1 oder 2 kleinere Foramina nach innen durchgehen, wahrscheinlich für kleine Gefässe, vielleicht auch für kleinere Nervenäste, die sich bereits hier abspalten. Hafferl ('21) beschreibt ain Geckolabyrinth: "Bei einem Embryo von 0,5 mm Kopflänge sind nicht nur das Foramen acusticum 
anterius und posterius vollkommen voneinander getrennt, sondern es hat sich vom Foramen posterius noch eine ganz kleine Öffuung abgeschieden, durch die der Ramus neglectus in die Ohrkapsel eintritt."

Ich untersuchte viele japanische Reptilien und konnte an der grossen Anzahl derselben (Takydromus tachydromoides und Ophidia ausgenommen) stets das Vorhandensein der drei oder mehr Foramina acustica konstatieren.

\section{Material und Methode.}

Mein Untersuchungsmaterial besteht aus folgenden sechs Arten von japanischen Reptilien: Trionyx japonicus, Clemmys japonica, Eumeces latiscutatus, Gecko japonicus, Takydromus tachydromoides und einige Ophidien, näralich Natrix tigrina, Elaphe climacophora, Elaphe quadrivirgata und Agkistroden blomhoffii.

Als Fixierungsmittel wurde Formol und Formol-Alkohol angewendet. Zur Entkalkung brauchte ich 3-5\% igen Salpetersäure-Alkohol. Die Tiere wurden alle in Zelloidin cingebettet und in frontale und horizontale Scrienschnitte von 25-50 $\mu$ Dicke zerlegt. Zur Färbung habe ich die Doppelfärbung mit Hämatoxylin-Eosin angewendet.

Das folgende zeigt die Zahl der untersuchten Ohren ausgewachsener Tiere.

1. Trionyx japonicus T. u. S. 7

2. Clemmys japonica " 10

3. Gecko japonicus (Dun. u. Bir.) 6

4. Eumeces latiscutatus (Hall.) 10

5. Tachydromus tachydromoides (Schlegr.) 6

6. Ophidien 10 Total

49 Ohren

Aus den zwei Ohrkapseln von Clemmys und Eumeces latiscutatus habe ich zwei 25-33 fach vergrösserte Wachsplattenmodelle angefertigt; für das Anbringen der Richtzeichen benützte ich den Beschneiderritzer von $\mathrm{Okajima}$.

\section{Eigene Befunde.}

\section{Trionyx japonicus T.u. S.}

Serie 1. Rechtes Ohr.

Der vordere und hintere Teil der medialen Ohrkupselwand besteht ganz aus Knochenmasse ; ihr zentraler Teil ist knorpelig, während die peripheren Abschnitte knöchern sind. Das Foramen acusticum anterius 
ist kleiner als das Foramen ac. posterius und im vorderen Knochenteil nah dem Boden der Schädelhöhle gelegen. Hier bemerken wir noch von vorn nach hinten eingereiht die drei klcinen Foramina acustica media, ferner hinten davon von oben nach unten übereinander liegend die zwei Löcher in der Knorpelmasse: oben das kleine Foramen endolymphaticum und unten das grosse Foramen acusticum posterius. Weit nach hinten vom letzteren sehen wir auch in der Knorpelmasse das kleine Foramen glossopharyngeum, wodurch der N. glossopharyngeus in die Ohrkapselhöhle eindringt und lateral durchläuft, um dann durch den hinteren Teil der lateralen Kapselwand hindurch hinauszugehen.

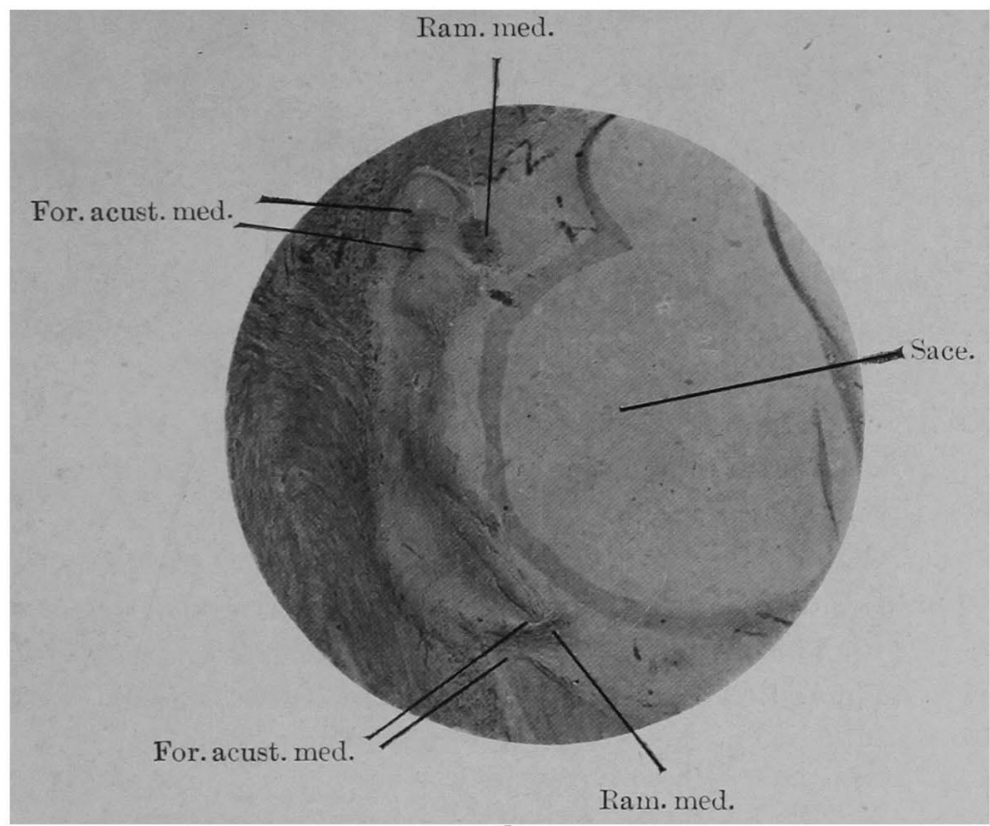

Fig. 1.

Horizontalschnitt durch die zwei Foramina acustica media der rechten Ohrkapsel. Trionyx japonicus.

Das Acusticus-Ganglion steht an der medialen Ohrkapselwand liegend mit dem Faciglis-Ganglion durch den N. acusticus in Verbindung. Von ihm vorne tritt der Ramus anterior und medius aus und setzt sich nach hinten direkt in den Ramus posterior fort. Der Ramus anterior ist kleiner als der Ramus posterior, er verläuft, nach seinem Austritt aus dem Foramen acusticum anterius, nach oben und rorn, gelangt an die mediale Wandung der Utriculus, gibt hier einen kurzen, ziemlich grossen Zweig dem Recessus utriculi ab und teilt sich dann in zwei Endäste, von denen der eine zur vorderen, der andere zur lateralen Ampulle tritt. 
Von dem Ganglion acusticum anterius entspringen bie drei dünnen Nerven, die durch die Foramina media in die Ohrkapselhöhle eintreten und lateral sich hinziehend an den medioventralen Teil des Sacculus gelangen. Der Ramus posterior bildet dagegen intrakranial kein Ganglion, sondern tritt durch das Foramen acusticum posterius in das Cavum cochleare ein und schwillt hier zu einem Ganglion an. Der Ramus posterior gibt nach seinem Durchtritt des Foramen posterius vorn einen, hinien vier Nerren ab. Der vordere grössere Ast zieht an der medialen IVand des Carum cochleare abwärts zum sacculus. Ein kurzer von den hinteren Nerven verläuft nach unten und hinten zur Norvenendstelle der Pars basilaris, der andere, mässig starke zieht entlang der medialen Wrand der Lagena zu deren Macula acustica. Der Endast des dünnen Ramus posterior zieht wach der hinteren Ampulle, teilt sich in zwei Äste, von denen der eine zur Pars neglecta und der andere zur Crista ampullae posterioris geht.

Serie 2. Linkes Ohr.

Der vordere und hintere Teil der medialen Ohrkapselwand besteht aus Knochenmasse, während der mittlere aus Knorpel sowie Knochen zusammengesetzt ist wie bei Serie 1. An der imneren Fläche der Ohrkapsel und zwar in der Gegend, wo dieselbe am Boden stösst, liegt eine Knochenöffnung, dis Foramen acusticum anterius für den Ramus anterior. An der medialen Wand bemerkt man die Acusticuswurzel, die direkt hinter dem $\mathrm{X}$. facialis liegt und durch das Foramen acusticum in lateraler Richtung aus der Schädelhöhle heraustritt, um gleich danach zu einem Ganglion anzuschwellen. Am vorderen, unteren und knöchernen Abschnitte der medialen Wand liegen hintereinander die drei Foramina acustica media, dessen hinterstes am kleinsten ist und die zum Durchtritt der Rami medii bestimmt sind. Am äussersten Ende von ihnen und im Knorpelteil findet sich noch eine kleine Öffnung, das vierte Foramen acusticum medium, die auch für einen Ramus medius bestimmt ist. An der hinteren unteren und knorpeligen medialen Ohrkapselwand liegt eine grijssere Öffnung, das Foramen acusticum posterius, durch das der Ramus posterior passiert. Oben davon sehen wir das knorpelige Foramen endolymphaticum und ferner hinter diesem das Foramen glossopharyngeum.

Vom länglichen Acusticus-Ganglion nach vorn gehen der Ramus anterior und vier Rami medii, nach hinten der Ramus posterior. Der Ramus anterior zieht lateral und tritt durch den oben erwähnten Knochenkanal hindurch zum Cavum restibulare, um sich in den Recessus utriculi und die beiden Ampullen zu verzweigen. Die dünnen Rami 
medii gehen durch die Foramina media zu der unteren medialen Flïche des Sacculus. Der krïftige Ramus posterior verläuft nach hinten unten und gibt den Hauptast zum sacculus ab, und zerfällt danach in den stärkeren Ramulıs lagenae und den schwächeren Ramulus partis basilaris sowie Ramulus neglectus, und endlich in den dünnen Ramulus Ampullae posterioris.

Serie 3-4. Rechtes und linkes Ohr.

Diese beiden Serien zeigen ein ungeführ gleiches Verhältnis. Der vordere und hintere Teil der medialen Ohrkapselwand sind aus Knochen und der mittlere aus Knorpel zusammengesetzt. Das Acusticus-Ganglion an der medialen Wand steht ventrokranial mit dem Facialis-Ganglion in Verbindung. Yon ihm nach vorn tritt der Ramus anterior durch das Foramen acusticum anterius in das Cavum vestibulare ein, der über den Recessus utriculi hinweg nach vorn oben verläuft und begibt sich zu dem Recessus utriculi und den vorderen und lateralen Ampullen; nach hinten setzt sich das Ganglion posterius in den Ramus posterior fort, der nach seinem Austritt aus dem Foramen acusticum posterjus, nach hinten zur Macula sacculi, Crista acustica partis basilaris, Macula lagenae und Macula neglecta zieht und endlich als ein dünner Nervenzweig an der Ampulla posterior endet. Wir finden in den beiden Serien die hintereinander liegenden drei Foramina acustica media, besonders ist das hinterste auf der linken Seite ziemlich gross, wobei die drei kleinen Nervenzweige nach dem Durchtritt durch diese Foramina alle zum Sacculus eintreten. Im oberen Teil der medialen knorpeligen Wand findet sich das Foramen endolymphaticum, das zwischen dem Foramen posterius und dem hintersten Foramen medium liegt.

Serie 5-6. Rechtes und linkes Ohr.

Die beiderseitigen Serien verhalten sich fast gleich. An der medialen Ohrkapselwand bemerken wir die sechs Löcher, das Foramen acusticum anterius und posterius, die zwei Foramina acustica media, das Foramen endolymphaticum und endlich das Foramen glossopharyngeum. Unten öffnet sich in Knochensubstanz das Foramen acusticum anterius, hinten von diesem die zwei Foramina media auch in Knochenmasse, von denen das vordere kleiner als das hintere ist. Ferner hinten von den oben erwähnten Foramina, von oben nach unten gereiht die drei Löcher im Knorpel; das obcre kleine ist für den Ductus endolymphaticus, das zweite untere grössere für Ramus posterior und das kleine letztere für $\mathrm{N}$. glossopharyngeus bestimmt.

Bezüglich der Zweige des Acusticus läuft der Ramus medius, nach seinem Durchtritt aus den Foramina acustica media, zum Sacculus. Der 
Ramus anterior dringt durch das Foramen anterius in die Ohrkapselhöhle ein und gibt hier einen Ast zum Recessus utriculi ab; dann rerzweigt er sich in die zwei İste, von denen der eine zur Ampulla anterior and der andere zur Ampulla lateralis tritt. Der Ramus posterior, der sich immer an der hinteren Formenwand dicht anlegt, teilt sich nach dem Durchgehen durch das Foramen posterius in zwei Aste, von denen der eine -ich zum Sacculus begibt und der andere wieder in vier Zweige zerfällt, die zur Papilla partis basilaris. Macula lagcnae, Nacula neglecta sowie Cristal ampullae posterioris gehen.

Serie 7. Linkes Ohr.

Man bemerkt zwei Foramina media in Knochen-ubstanz der medialen Ohrkapselwand, deren rorderes gröser als das hintere schen dem hinteren Formen medium und Foramen posterius sielit man das Foramen endolymphaticum in Knorpelmisse. Dicht an der medialen Wand liegt das (ianglion acusticum und ron ihm gehen der Ramus anterior und posterior aus; die zwei Rami medii treten durch die entsprechenden Foramina acustica in die Ohrkapselhöhle hinein.

Ler Ramu: medius des Acusticus endet nach dem Austritt der Foramina media im sicculus. Der Ramus anterior und posterior verzweigen sich in gleicher iVeise wie bei obigen serjen.

\section{Clemmys japonica T. u. S.}

Serie s-!. Rechtes und linkes Ohr.

Der rordere und hintere Abschnitt der medialen Ohrkapselwand bestehen aus Knochensubstanz, wie beim Trionyx, während der mittlere grosse Teil knorpelig ist. Hier erkennt man die drei Foramina acustica. Das grösere Foramen acusticum anterius liegt in der rorderen Knochensubstauz, wäbrend das griosste Foramen posterius im hinteren Knorpelteil sich befindet. Zwischen diesen zwei Foramina befindet sich das kleinste Foramen acusticum medium in der vorderen Knochenmasse. Hinten oben daron liegt das Foramen endolymphaticum im Knorpelteil. Man bemerkt noch ein kleines Foramen glosso pharyngeum in hinteren Knorpelteil. Das Acusticus-Ganglion schwill kurz nach seinem Austritt aus dem Gehirn zu einem, deutlich in zwei Abschnitte geteilten Knoten an, der nach vorn den zum Torhof verlaufenden Ramus anterior sowie den Ramus medius abgibt und nach hinten den dicken Ramus posterior. 
Über die Foramina acnstica media an der ()hrkajsel von Reptilien.

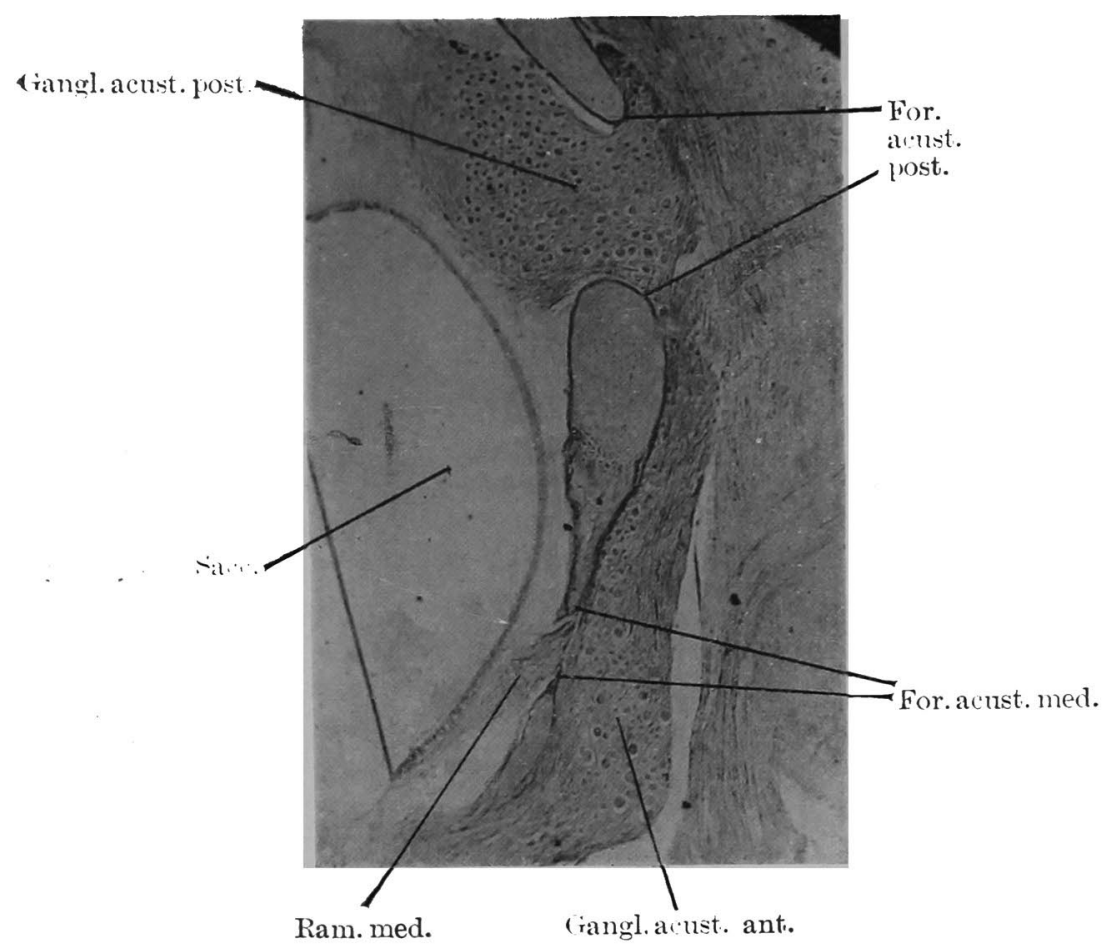

Fig. 2.

Horizntalschnitt durch das Foramen acusti:um medium und posterius der linken Ohrkajsel. Clenmy japonica.

Der Ramus medius des Acusticus endet nach dem Durchtritt des Foramen medium im Sacculus wie beim Trionyx. Der Ramus anterior und posterior passieren die entsprechenden Foramina acustica; der vordere gelangt zu dem Recessus utriculi und den lateralen und vorderen Ampullen, wïhrend der hintere sich in fünf Zweige, in den Ramulus sacculi. Ramulus partis basilaris, Ramulus lagenae, Ramulus neglectus unrl endlich in Ramulus ampullae posterioris verzweigt.

Sorie 10-11. Rechtes und linkes Ohr.

Die beiderseitigen Ohrkapseln sind fust gleich aufgebaut. Der rordere breite und hintere schmale Abschnitt ihrer medialen Trand sind knïchern und der mittlere grosse knorpelig. Der kurze, ziemlich dicke Ramulus utriculi erreicht von unten her den medialen Boden des Recessus utriculi und breitet sich an dessen Nervenendstelle aus. Der ziemlich kräftige Ramulus ampullae lateralis z:eht bis zur Aussenfläche der lateralen Ampulle. Der Ramus sacculi zerfällt medial von Recessus utriculi in zwei $Z_{w}$ ige, von denen der eine abwärts zum Sacculus zieht, 
der andere writer nach hinten zur Cochlea verläuft. Der schwache Ramus medius entstammt dem Ganglion acusticum anterius und breitet sich gleich nach seinem Austritt aus dem Foramen medium, absteigend an der medialen Wand des Sacuulus aus.

Dic Verzweigung des Acusticus verhïlt sjch auch fast gleich wie bei den Serien s-9.

Serie 12-13. Rechtes und linkes Ohr.

In dicsen beiden Serien beteiligt sich dic Knorpehmasse an der Bildung der medialen Wind viel umfangreicher als bei den rorigen Serien. Dats Foramen acusticum anterius und medium liegen in der vorderen Knochensulstanz. Das Foramen anterius an der linken Seite ist wrisser als an der rechten, während links das Foramen medium kleiner als rechts ist. Weiter nach hinten zeigt sich das grosse Foramen po-terius und oberhalb desselben das kleine Foramen endolymphaticum, die beide sich in der Knorpelmasse rortinden.

Das Ganglion acusticum liegt dicht an der medialen Wand und teilt sich in zwei Ganglien. Die aus dem Ganglion anterius austretenden zwei Nervenïste. der Ramus anterior und medius, gehen siimtlich durch die entsprechenden Foramina acustica zum Carum vestibulare und gelangen von hier, der vorder' zu den beiden Ampullen und dem Ctriculus, der hintere zum silcculus. If rom hinteren Ganglion entspringend. Ramus pusteriur tritt durch das Foramen posterius hindurch in das Carum cochleare, teilt sich dann in fünf Zweige und endigt in Macula sacculi, Papilla partis hasilirris. Macula lagenae, Macula neglecta und Crista ampullae posterioris.

Serie 1t-15. Rechtes und linkes Ohr.

Das Foramen anterius und medium befinden sich beiderseits auf dem durchaus aus Knochen bestehonden Abschnitt der medialen Ohrkaps.lwand, wälnend las Foramen posterius und endolymphaticum sowie glossopharyngeum im knorpeligen ITandteil liegen. Die drei Foramina acustica zeigen sicl auf der linken Seite etwats kleiner als auf der rechten.

In Bezug auf die Verbreilung des Acuticus endet der Ramus medius nach dem Durchgehen des Foramen medium im Sisculus. Der Ramus anterior und posterior verteilen sich in gleicher Weise wie bei den rorigen Serien.

Im folgenden möchte ich das Wachsplattenmodell der Ohrkajsel von Clemmys betrachten, das aus der rechten seite stammt und in 25 facher Vergrösserung angefertigt wurde.

Die mediale Wand der Ohrkapsel wird aus Knochen und Knorpel zusammengesetzt, so das- vorn das Prooticum. hinten das Opistonticum, 
und zwischen diesen beiden der Schneckenknorpel liegen; der letztere kommt durch das Zusammenfliessen eines von oben vorn und eines von oben hinten je herabsteigenden Schenkels zu stande. Zwischen d'n beiden Schenkeln liegt das Supraoccipitale, sich von oben heralss'nkend.

Die mediale Wand lïsst sich in 'ine obere grössere und eine untere kleinere Hälfte unterscheiden; dir erstere entspricht innen dem Cavum vestibulare, die letztere dem Cavum cochleare. Die obere Hälfte, besonders ihr mittlerer Teil, buchtet sich in die Schädelhöhle stark hinein. Am vorderen oberen Wandteil sieht man einen fast horizontal liegenden langen Wulst, die Prominentia semicircularis anterior. Nach unten hinten davon ist ungeführ in Mittelhöhe, cine grosse horizontale Erhebung auffïllig, die Prominentia utriculosaccularis. Ventralwiirts davon geht die mediale Wand allmählich in dio breite flache Vertiefung über. Wir finden im ganzen fünf Löcher. Oberhalb der Mitte der Prominentia utriculosaccularis bemerkt man das kleine eingezogene Foramen endolymphaticum, das die grösste anteroposteriore Länge von $2,5 \mathrm{~mm}(0,1 \mathrm{~mm})$, die grösste dor'soventrale Breite von $15 \mathrm{~mm}(0,6 \mathrm{~mm})$ hat. Weiter unten davon sieht man von vorn nach hinten die vier Foramina. Das vorderste, unregelmässig viereckjge Foramen acusticum anterius liegt im Prooticum, besitzt die grösste Länge von $7 \mathrm{~mm}(0,28 \mathrm{~mm})$ und

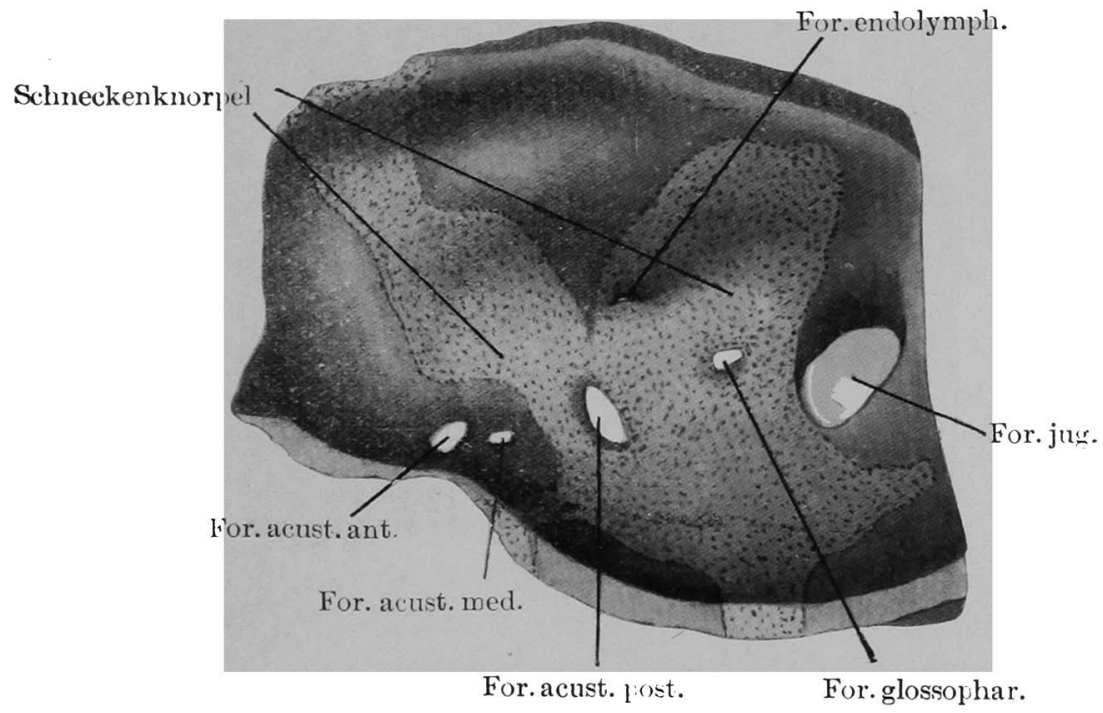

Fiır. 3.

Iediale Anicht des Modells der rechten Ohrkapsel. Cl(mminy ja|snica. 25 mal vergrössert modelliert und a uf $1 / 2$ verkleinert reproduziert. 


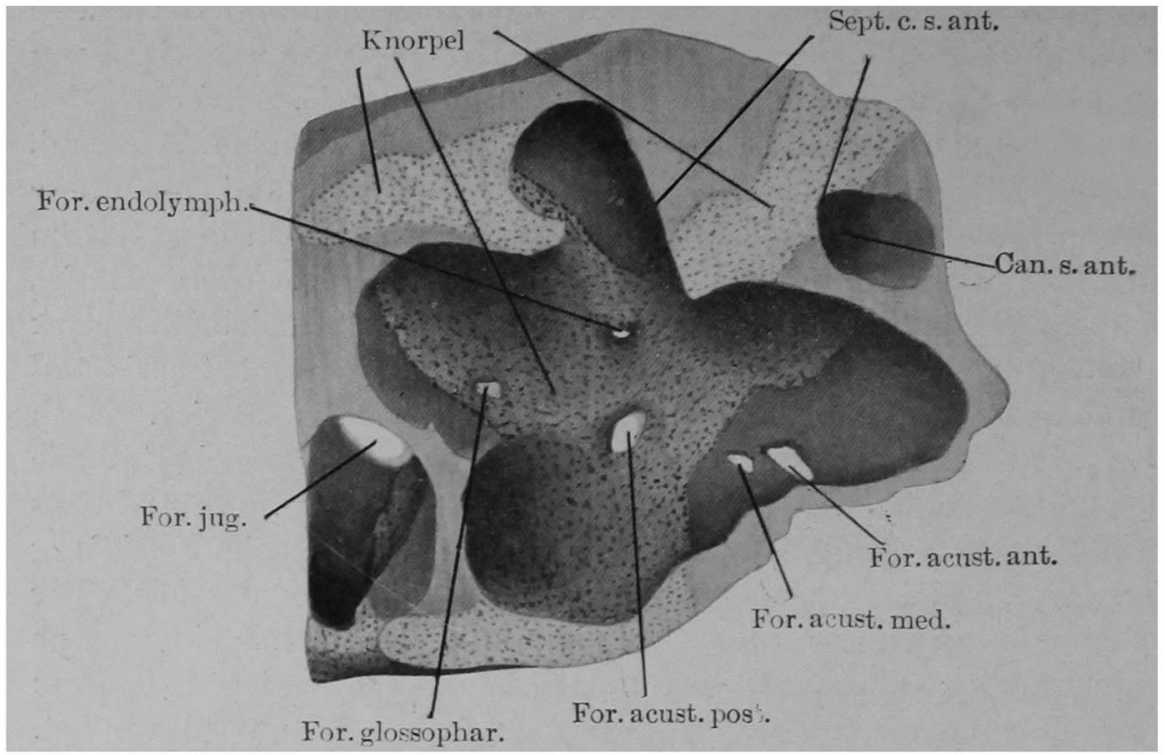

Fig. 4.

Suritalischnitt durch dasselbe Modell, mediale Häfte lateral gesehen.

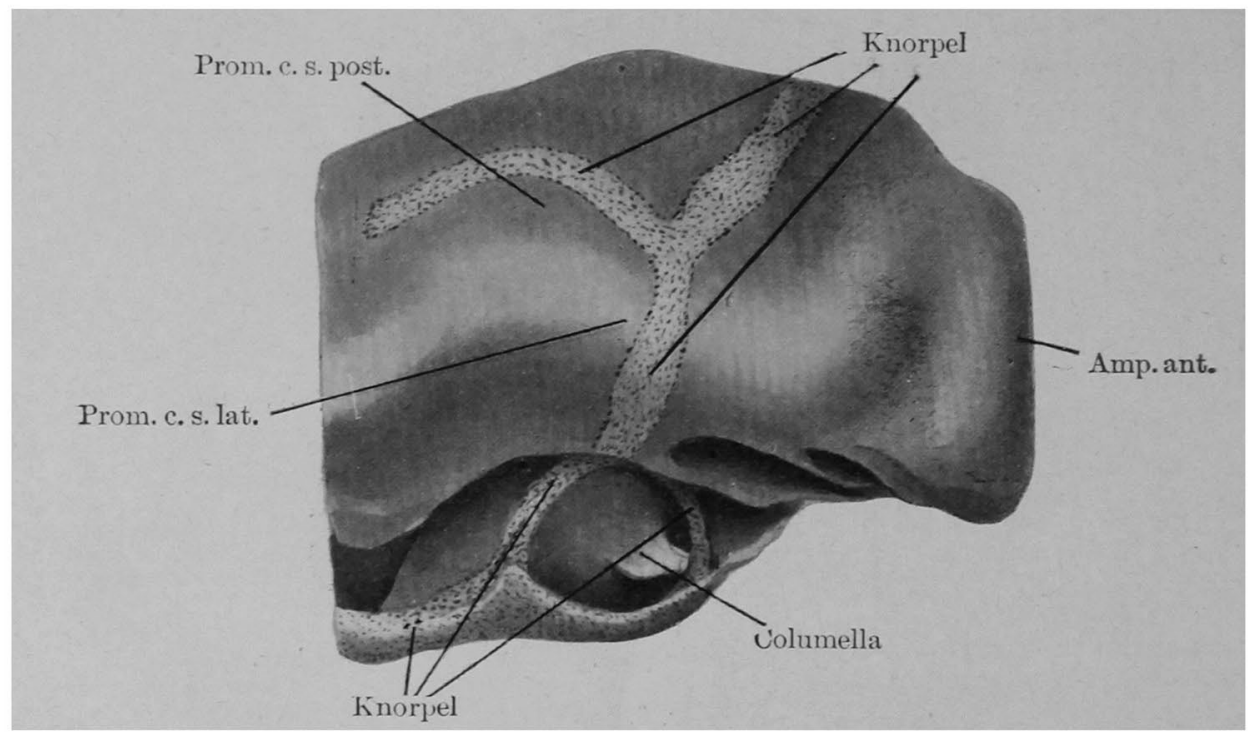

Fig. 5.

1).rale Ansicht desselben Morlells. 


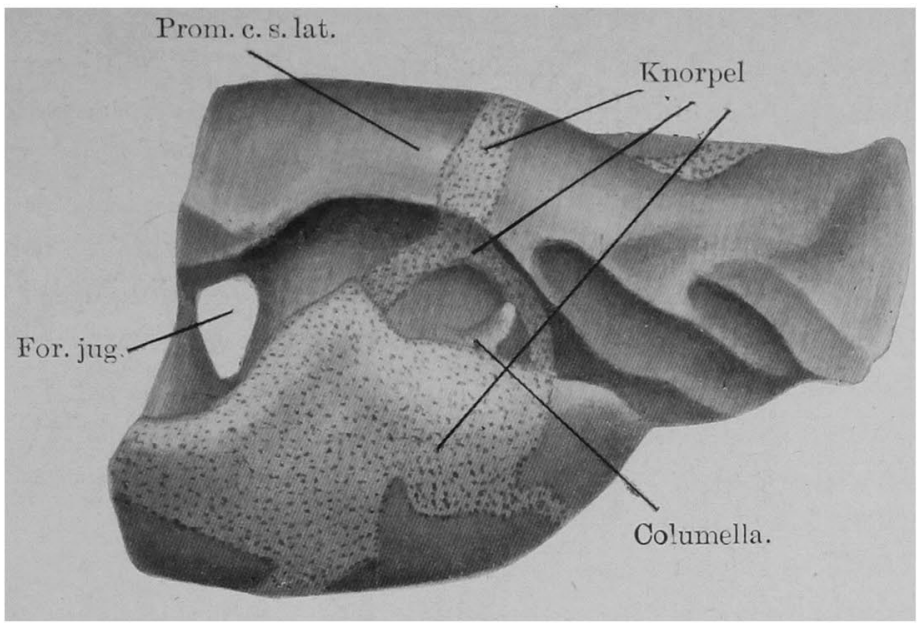

Fig. 6.

Ventrale Ansicht desselben Modells.

Breite von $4 \mathrm{~mm}(0,16 \mathrm{~mm})$; seine Lüngsachse ist von oben hinten nach tuten vorn gerichtet. Hinten von ihm auch auf dem Gebiet des Prooticums, findet sich das längliche Foramen acusticum medium, das eine Lïnge von $4 \mathrm{~mm}(0,16 \mathrm{~mm})$ und eine Breite von $3 \mathrm{~mm}(0,12 \mathrm{~mm})$ hat; seine Längsachse steht von hinten oben nach rorn unten geneigt. Das grösste Foramen acusticum posterius ist oval und findet sich weit hinter dem Foramen medium unten und etwas vorn rom Foramen endolymphaticum im Schneckenknorpel; es besit\%t die griisste Länge von $13 \mathrm{~mm}$ (0,52 $\mathrm{mm})$ und die grösste Breite von $(\mathrm{mm}(0,24 \mathrm{~mm})$. Seine Längsachse ist von oben vorn nach unten hinten gerichtet. Weit hinten oben davon findet man noch eine langgestreckte viereckige Öffnung im Knorpel, das Foramen glossopharyngeum, dessen Längsachse fast horizontal liegt; es besitzt eine Länge vou $6 \mathrm{~mm}(0,24 \mathrm{~mm})$ und eine Breite ron $3 \mathrm{~mm}$ (0,12 mm). Am hinteren Abschnitt der medialen Wand liegt ausserdem das grosse ovale Foramen jugulare, das als grösste Länge $35 \mathrm{~mm}(1,4 \mathrm{~mm})$ als grösste Breite $17 \mathrm{~mm}(0,68 \mathrm{~mm})$ hat; seine Lïngsachse steht von oben hinten nach vorn unten geneigt.

Die hintere Wand der Ohrkapsel trägt übereinander die zwei Foramina, ein oberes grosses Foramen ovale und ein unteres kleines Foramen rotundum, die beide unmittelbar in die Labyrinthhöhle einführen. Der Durchmesser des ersteren beläuft sich auf 15-14 mm (0,6$0,56 \mathrm{~mm})$, der des letzteren auf $13-9 \mathrm{~mm}(0,52-0,36 \mathrm{~mm})$.

Von der vorderen und mittleren Abteilung der ventralen Wand des Ohrkapselknorpels ziehen die zwei schmalen Knorpelbänder weiter zur 
ventralen Wand hin und verbreiten sich auf ler fust ganzen ventralen IVand der Pars cochlearis. An der lateralen IVand schliessen diese aufsteigenden zwei Schenkel die rundliche Columella auris zwischen sich ein und verbinden sich miteinander zu einem schmalen Band an deren oberem Rand; das letatere verlïuft nun vom mittleren Abschnitt der Prominentia semicircularis lateralis auf dor lateralen Ohrkapselwand nach oben und teilt sich wieder in zwei Schenkel, von denen der eine in die Promintia semicircularis posterior, der andere in den vorderen oberen Rand der medialen Ohrkapselwand übergeht.

Die Lünge des Septum senicirculare anterius betrïgt $36 \mathrm{~mm}$ $(1,44 \mathrm{~mm})$, die des Septum posterius $30 \mathrm{~mm}(1,2 \mathrm{~mm})$ und die des Septum laterale $35 \mathrm{~mm}(1,4 \mathrm{~mm})$.

Serie 16-17. Rechtes und linkes Ohr.

In diesen beiden Serien bemerkt man beiderseits fast gleiches Verhalten.

Das Foramen anterius und medium zeigen hier keine Besonderheiten wie bei den anderen Serien, während das Foramen posterius viel grösser als anderswo ist. Der Ramus medius ist sehr klein und zieht nach seinem lustritt aus dem Foramen medium zum Saceulus. Der Ramus anterior geht entlang der lateralen Flïche des Ctriculus und gibt den Ramulus utriculi. Ramulus ampullae lateralis und anterioris ab. Direkt nach seinem Eintritt in die Ohrkapselhöhle bildet der Ramus posterior ein rundliches, ziemlich grosses Ganglion, von dem die fünf gewöhnlichen starken iste ausgehen.

Die Verteilung des Acusticus verhält sich wio bei den bisher beschriebenen Serien.

\section{Gecko japonicus (Dum. u. Bib.).}

Serie 18-19. Rechtes und linkes Ohr.

Diese beiden serien zeigen ein ungeführ gleiches Verhältnis. Die mediale Ohrkapselwand besteht durchaus aus Knochensubstanz und ihr ziemlich dickes Periost enthält viele Pigmente. Das Foramen acus. ticum anterius liegt an ihrem vorderen Abschnitt mit dem gleichnamigen Ganglion und ist für den Durchtritt des Ramus anterior bestimmt. Nach hinten davon liegt das kleinste Foramen medium und nach hinten, etwas unterhalb das grosse Foramen posterius. Das Foramen medium ist an der linken Seite kleiner als an der rechten. Das Foramen endolymphaticum liegt oben am zentralen Teil der medialen Wand und ist sehr klein, erweitert sich aber bald zu einer schrïg nach vorn und oben aufsteigenden Höhle. 


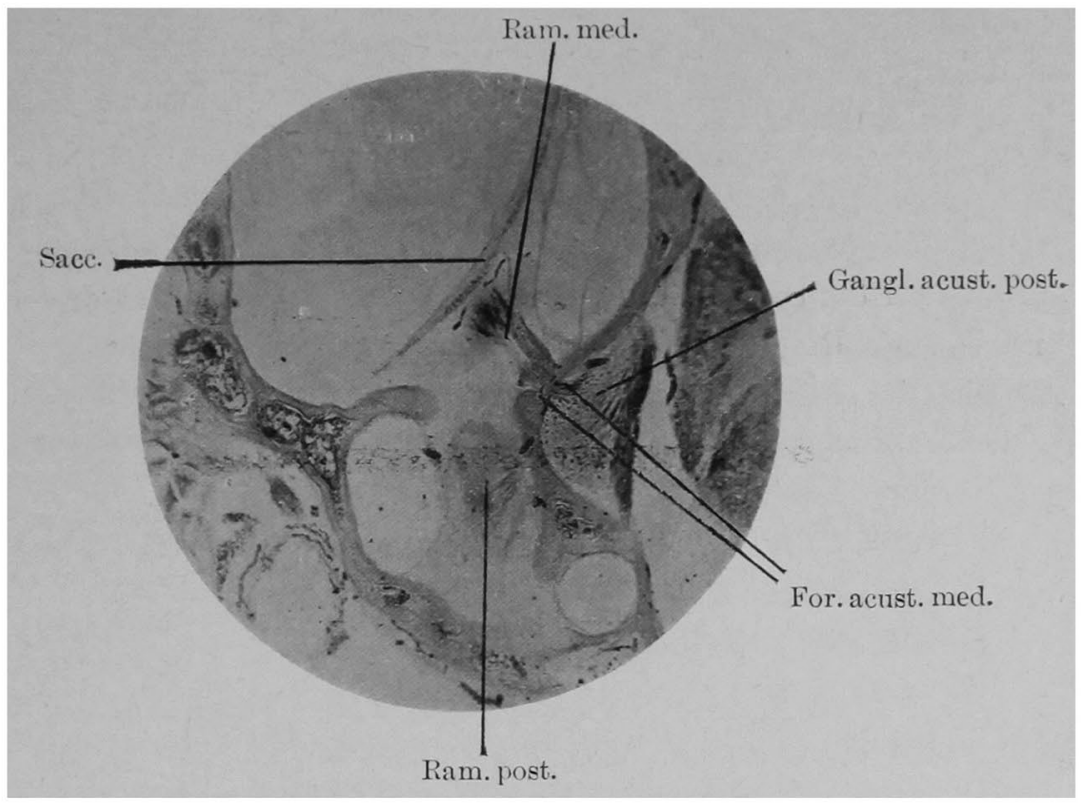

Fir. 7.

Frontalichnitt durch das Foramen acusticum medium (ler linken Ghrkapsi l. Gecko japonicus (Dum. u. Bir.).

Das Ganglion acusticum liegt dicht an der medialen Wand. Ton ihm geht nach rorn rer Ramus anterior aus, gelangt nach seinem Austritt aus dem Foramen anterius in das Carum vestibulare und rerteilt sich im Ctriculus. Ampulla lateralis und anterior. Der Ramus posterior bildet nach dem Durchtritt durch das Foramen posterius im Cavum cochleare ein rundliches (ianglion posterius. Der Ramus posterior gibt vorn einen, hinten vier Tervenzweige ab. Der vordere Ast geht nach oben bis zur medialen Wand des Sacculus und innerviert die Macula sacculi. Ton den hinteren Zweigen verlïuft der eine zur Papilla partis basilaris, der andere zur merlialen Wind der Lagena; endlich gehen die zwei Zweige nach hinten und endigen in Macula neglecta und Crista acustica posterior. Der aus dem ranglion posterius entspringende dünne Ramus medius geht nach seinem Austritt vom Foramen medium zum sacculus und verloreitet sich in Macula sacculi.

Serie $20-21$. Rechtes und linkes ()hr.

Am vorderen Abschnitt der medialen Ohrkapselwand befindet sich ein schmales, von vorn oben nach hinten unten verlaufendes Knorpel- 
band, das direkt mit der hinter dem Foramen posterius liegenden huorpelzone sich verbindet. Das Foramen acusticum anterius sowie medium und Foramen endolymphaticum befinden sich im völlig knöchernen Abschnitte der medialen Wand, während das Foramen posterius vorn grösstenteils im Gebiete des Knochers und hinten zum kleinen Teil im Knorpel liegt. Torn -ieht man den starken Ramulu-recessus utriculi, ampullae lateralis und anterinis, hinten den sehwächeren Ramus medius und starken Ramus pusterior. Der Ramu, medius greht nach seinem Austritt des Foramen medium zur Macula sacculi, und der Ramus posterior zerfällt nach dem Durchgehen des Foramen posterius in fünf gewöhnliche zweịe.

Bezüglich der Verteilung de; Ramus anterior und posterior ist hier kein grosser Lnterschicd von den obigen surien zu finden.

Serie 22-23. Licchtes und linkes Ohr.

Die mediale Ohrkapselwand bestelt aus dem Knochen sowie Knorpel wie bei den surien 20-21. Das Foramen anterius und medium -ind miissig gross und liegen in Knochenmase. wähend dat Foramen jwsterius zu seinem hinteren kleineren Teil in Knorpelsubstanz sich befindet. Das Foramen endolymphaticum ist am gris-ten von allen untersuchten Surien ile-Geckolaliviuthes.

Die Verteilungsweiso les Acusticus stimmt vollständig mit denen der obigen Serien überein.

\section{Eumeces latiscutatus ।Hall.।.}

Surie 24-25. Rechtes und linkes ()hr.

Der vordere und hintere Teil der medialen Ohrkapselwand besteht aus Knochen und zwischen den beiden verläufi ein schmals Knorgelland von oben nach unten. Die Knochunsubstanz ist mit zahlreichem Pigment versehen, wie beim Geckolabyrinth, und ron ziemlich dickem Periost bekleidet.

Das Foramen acusticum anterius ist ziemiich gross und liegt in vorderer Knochenmasse. Hinten davon sieht man im Knochen zwei Foramina, das kleine Foramen medium und das grosse Foramen fosterius. Oben rom letzteren befindet sich das knöcherne kleine Foramen endolymphaticum, has nach vorn olen sich erweitert und eine längliche Höhle bildet. 


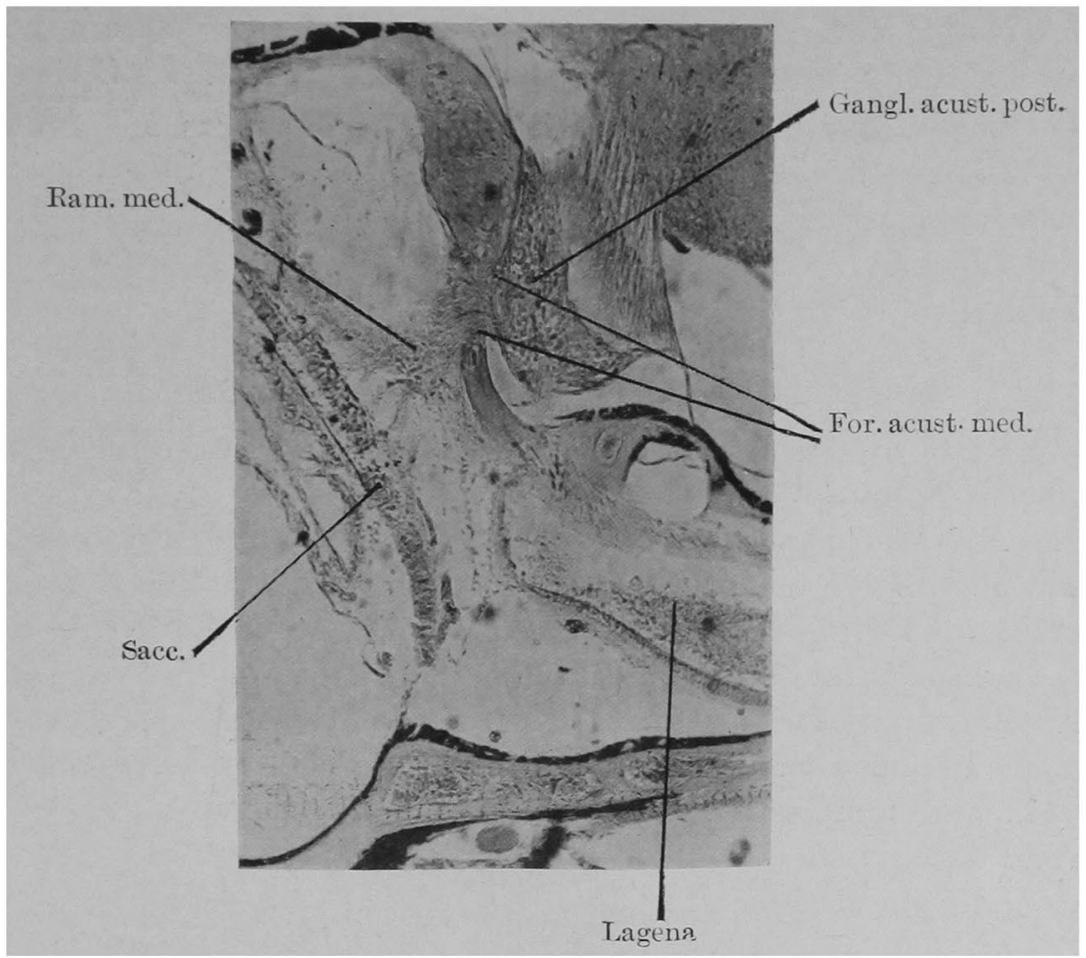

Fig. $\delta$.

Frontalschnitt durch das Foramen acnsticum medium der linken Obrkapsel. Eumeces latiscutatus.

Das Ganglion acusticum liegt dicht an der medialen Ohrkapselwand. Der Ramus anterior tritt durch das Foramen anterius in das Cavum vestibulare und gelangt zur Ampulla anterior, lateralis und dem Utriculus. Vom Ganglion posterius gehen der kleine Ramus medius und posterior aus; der erstere entspringt vom dorsalen Teil dieses Ganglions und zieht sich nach dem Durchgehen des Foramen medium an der medialen Wand des Sacculus hin, wïhrend der vom hinteren Teil des Ganglions gehende Ramus posterior, nach seinem Austritt aus dem Foramen posterius, in zwei Äste zerfällt, von denen der eine, Ramus sacculi, sich in mehrere kleine Nervenfaserbündel teilend nach oben zieht und sich an der medialen Wand des Sacculus ausbreitet, der andere teilt sich in zwei Äste, von denen der eine wieder in den stärkeren Ramulus lagenae und den schwächeren Ramulus partis basilaris zerfällt, während der zweite über die Pars basilaris hinweg zieht und einen Zweig zur Macula neglecta gibt, um endlich an die Unterfläche der Ampulla posterior zu gelangen. 
Nun möchte ich ein Wachsplattenmodell der Ohrkapsel ron Eumeces latiscutatus beschreiben, das aus der linken Seite dieser Serie stammt und 33 fach vergrössert angefertigt wurde.

Die mediale Wand der (Ohrkajsel wird von drei Knochen zusammengesetzt, vorn rom Prooticum, hinten rom Opistoticum und oben vom Epistoticum. Zwischen diesen drei verlüuft cin senkrechtes schmales Y-förmiges Knorpelband. Die mediale Ohrkapselwand ist in zwei Abschnitte einzuteilen, cinen grösseren dorsalen und einen kleineren ventralen. Der ventrale Teil ist rom dorsalen giinzlich von dorsal her überlagert und nach medial ausgehöhlt. Der dorsale Teil hat dic Form eines horizontalen Zylinders.

Auf dem dorsalen 'Teil verlüuft die Prominentia utriculosaccularis von hinten oben nach vorn unten, buchtet sich stark in die Schädelhöhle hinein und wird nach vorn allmählich flach. Auf dem ventralen 'Teil bemerkt man im ganzen vier Lijcher. Das cine davon liegt im konkaven Abschnitt unmittelbar oberhalb der Prominentia; es ist das kleinste lange Foramen endolymphaticum und hat die wrioste Länge ron $4 \mathrm{~mm}$ $(0,12 \mathrm{~mm})$ und grösste Breite von $1,5 \mathrm{~mm}$ (0,045 mm). Weiter unten vorn davon und direkt unter dieser Prominenz finden sich hintereinander die drei Foramia acustica. Das längliche, grösste Foramen

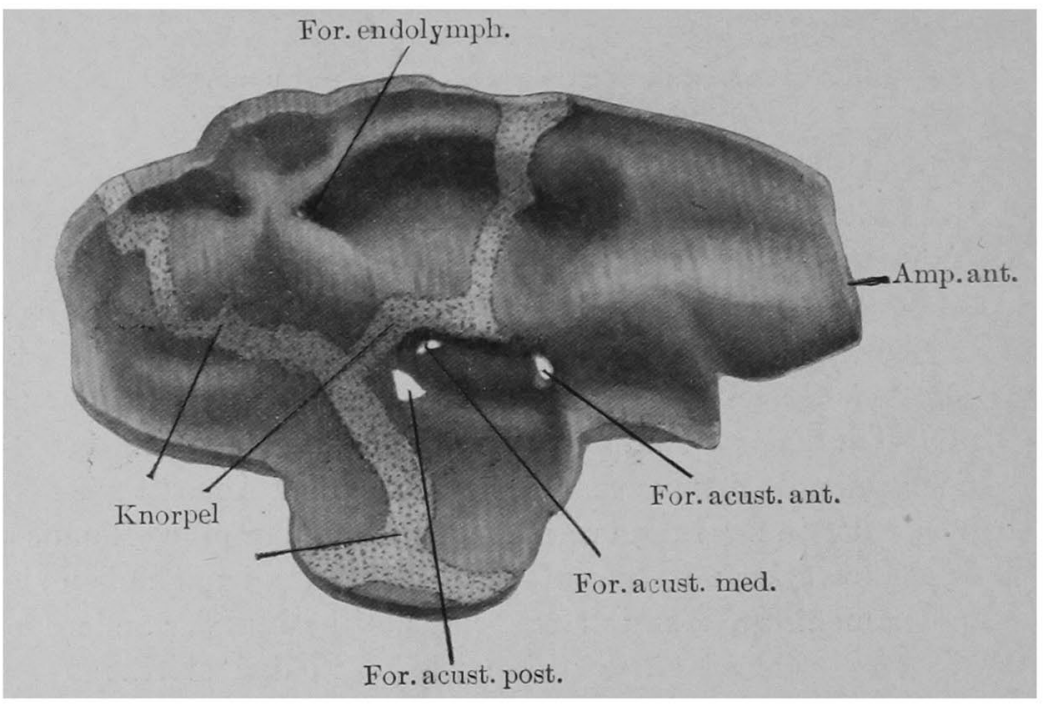

Fig. 9.

Mediale Ansicht des Modells der linken Ohrkapsel. Eumeces latiscutatıs. 33 mal vergrössert modelliert und auf 2,3 verkleinert reproduziert. 
Über die Foramina ar:ustica media an der Ohrkapsel von Reptilien.

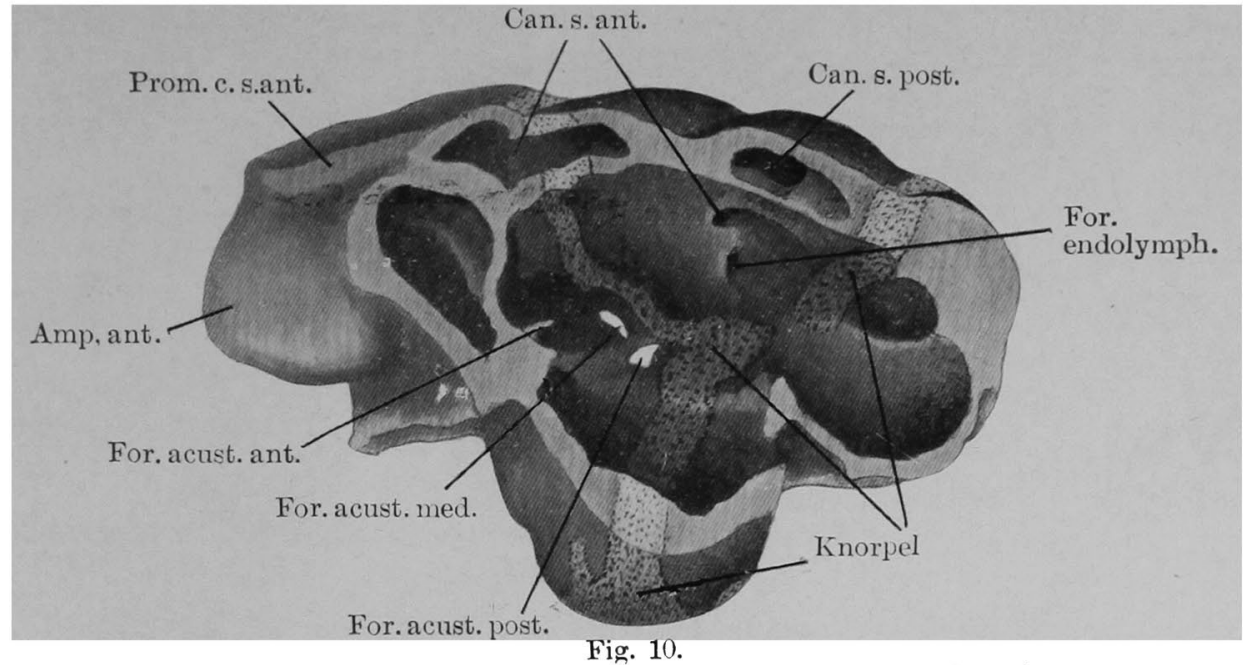

Sagittalschnitt durch dasselbe Modell, mediale Hiifte lateral gesehen.

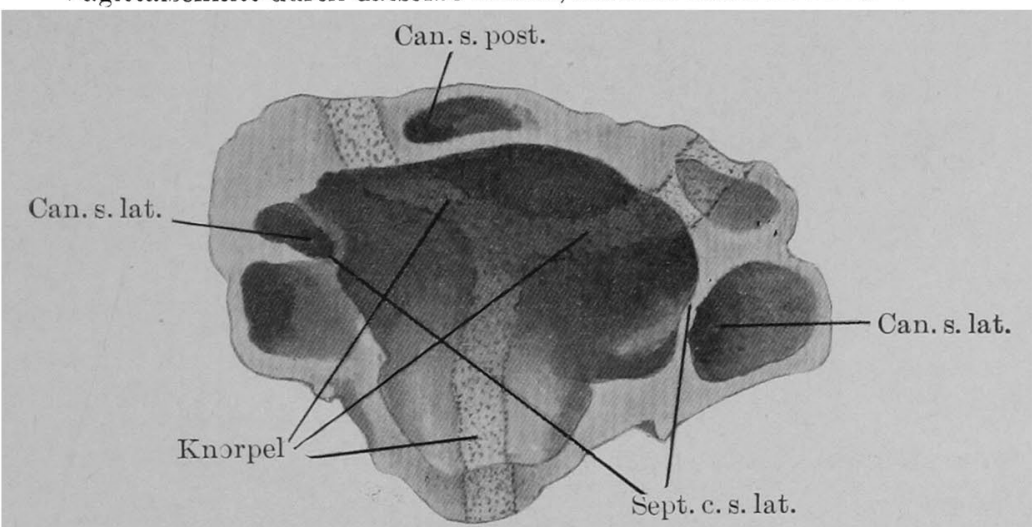

Fig. 11.

Sagittalschnitt durch dasselbe Mołcll, laterale Häfte medial gesehen.

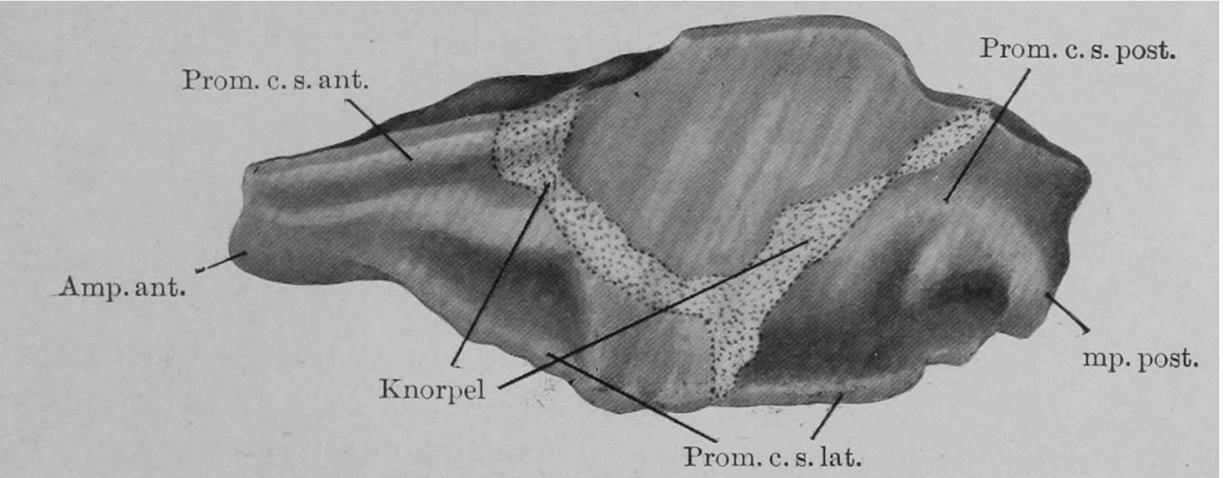

Fig. 12 .

Dorsale Ansicht desselben Modells. 


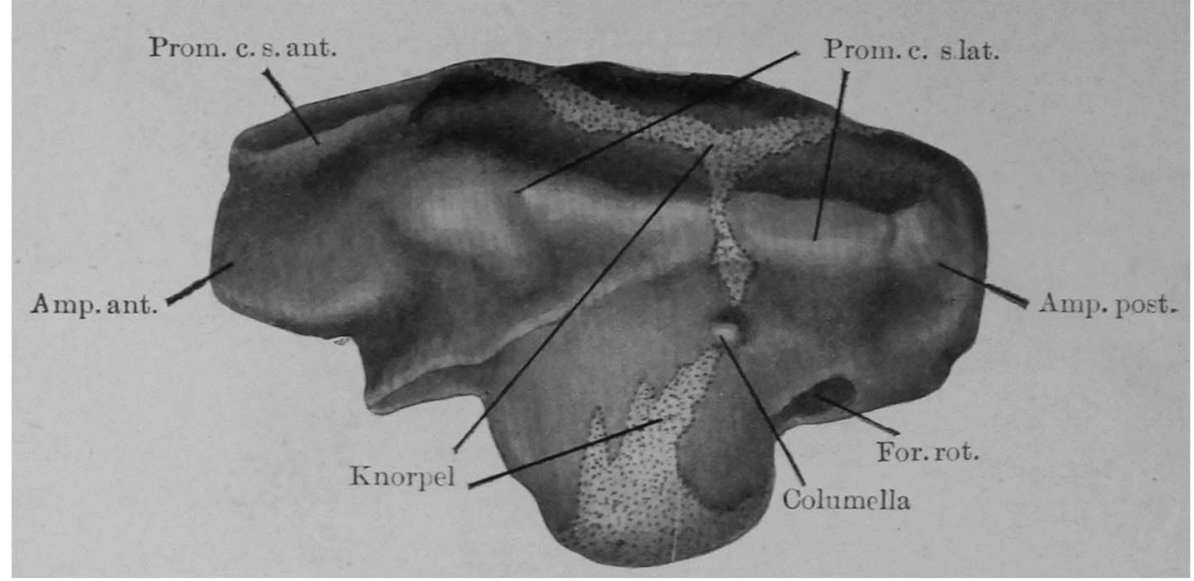

Fin. 13.

Ventrale Ansicht desselben Modells.

acusticum anterius steht mit -einer Längsachse von oben vorn nach unten hinten werichtet und besitzt als gröste Länge $8 \mathrm{~mm}(0.2-1 \mathrm{~mm})$, als grösste Breite $2,5 \mathrm{~mm}(0,05 \mathrm{~mm})$. Silch hinten oben von dies das kleinere dreieckige Foramen medium, das mit seiner spitze nach hinten unten greneigt steht und eine Länge ron 5 $\mathrm{mm}(0,15 \mathrm{~mm})$, eine Breite der Basis ron $3 \mathrm{~mm}(0,(19 \mathrm{~mm})$ hat. Das Foramen josterius ist oval und findet sich unweit vom Foramen medium, nach hinten unten davon: seine Längsalch; ist von oben hinten nach vorn unten geneigt. Er besitzt als gröstt. Länge $5 \mathrm{~mm}(0,15 \mathrm{~mm})$, als grösste Breite $3 \mathrm{~mm}$ $(0,09 \mathrm{~mm})$.

Am unteren Abschnitte des hinteren Rande: der Ohrkapsel befinden sich noch zwei Foramina übereinander, das Foramen ovale und dis, Foramen rotundum, welche beide durch einen dünnen Knochenbalken voneinander getrennt siud.

Ton der mittleren Abteilung der ventralen Ohrkajselwand steigt ein breites Knorpelband weiter auf der lateralen konvexen Wand der Pars cochlearis auf und durchquert die horizontale Prominentia semicircularis lateralis; danach teilt ss sich in zwei Schenkel, von denen der eine nach der Prominentia semicircularis anterior zieht, während der andere in die Prominentia semicircularis posterior und den dorsalen Rand der medialen Ohrkap-elwand übergeht. Zwischen den beiden Schenkeln eingefasst liegt das Epistoticum.

Die Länge des Septum semicirculare anterius beträgt $61 \mathrm{~mm}$ (1,S4 mm) und die des Septum laterale $55 \mathrm{~mm}(1,63 \mathrm{~mm})$; die des Septum posterius konnte ich am Modell nicht leicht messen. 
Serie 26-27. Rechtes und linkes Ohr.

Beiderseits verhält sich die Sache ganz gleich. Die medialo Wand besteht aus Knochen und Knorpelmasse; letztere erscheint als ein schmales Knorpelband. Die knöcherne Wand ist ziemlich dick und in ihr ist reichliche Pigmentierung zu konstatieren, jedoch nicht so deutlich wie beim Gecko. Die drei Foramina acustica liegen im Knochen. An der medialen Wand des Sacculus breiten sich der Ramus medius und Ramus sacculi aus; der erstere entspringt vom Ganglion posterius und gelangt, nach seinem Durchgehen des Foramen medium, an den Sacculus, der letztere geht von Ramus posterior aus und zieht sich auch zur Macula sacculi hin.

Die Ausbreitung des Acusticus ist überhaupt hier keinem grossen Unterschied von obigen Serien unterworfen.

Serie 28-29. Rechtes und linkes Ohr.

Die beiderseitigen knöchernen Labyrinthe sind fast gleich gebaut. Die mediale Wand besteht aus dünvem Knochen und Knorpelsubstanz, welch letztere sehr schmal ist wie bei den Serien 26-27.

Am vorderen knöchernen Abschnitt liegt das kleine Foramen endolymphaticum; ferner unten davon die zwei knöchernen Öffnungen; die eine ist das kleinere Foramen medium und die andere das grössere Foramen posterius. Das Foramen anterius liegt im vorderen knöchernen Abschnitt.

Die Verzweigung aller Nervenzweige des Acusticus zeigt das gleiche Verhältnis wie bei den oben beschriebenen Serien.

Serie 30-31. Rechtes und linkes Ohr.

Die mediale Wand der beiderseitigen Ohrkapsel ist im ganzen dünner, aber das Knorpelband breiter als bei den obigen Serien.

Am unteren knöchernen Abschnitte der medialen Wand liegen die zwei gleich grossen Foramina acustica, das Foramen anterius und posterius, und direkt nach vorn oben vom letzteren das Foramen medium, das mässig gross und zum Durchtritt des Ramus modius bestimmt ist.

Vom Ganglion acusticum, das sich an der medialen Wand dicht anlegt, gehen der Ramus anterior, posterior und medius aus. Der letztere kleine entspringt vom Ganglion posterius und gelangt, nach seinem Austritt vom Foramen medium, an den Sacculus. Der Ramus posterior zieht durch das Foramen posterius in die Ohrkapselhöhle, wo er zuerst an der medialen Wand des Sacculus nach oben, dann allmählich an der medialen Mand der Lagena nach unten zieht, wobei er einen Ast zur Pars basilaris abgibt, um endlich als dünner Nervenzweig zur Pars neglecta und Ampulla posterior zu gelangen. Der Ramus 
anterior gibt den Ramulus utriculi ab und teilt sich danach in zwei Aste, um in Crista ampullae lateralis sowie anterioris zu endigen.

Serie 32-33. Rechtes und linkes Ohr.

Der vordere und hintere Teil der medialen Ohrkapselwand bestehen grösstenteils aus Knochenmasse, während zwischen den beiden eine schmale Knorpelzone von oben nach unten verläuft.

Am oberen zentralen und knöchernen Abschnitte der medialen Wand befindet sich das Foramen endolymphaticum, nach unten davon liegen die drei Foramina acustica auf der vollkommen aus Knochenmasse bestehenden Wrand.

Die Verzweigung des Acusticus geschieht in ganz ähnlicher Weise wie bei den übrigen Serien.

\section{Tachydromus tachydromoides (Schleg.) und Ophidien.}

Die 6 Ohrkapseln vom Tachydromus und die 10 von Ophidien habe ich eingehend untersucht und konnte niemals ein Foramen acusticum medium konstatieren.

\begin{tabular}{|c|c|c|c|c|c|c|c|c|c|c|}
\hline \multirow{2}{*}{$\begin{array}{c}\text { Tierarten } \\
\text { Präparatnnmmer }\end{array}$} & \multicolumn{7}{|c|}{ Trionyx japonicus T. u. S. } & & \multicolumn{2}{|c|}{ Clemmys } \\
\hline & 1 & $\because$ & 3 & 4 & 5 & 6 & 7 & .8 & 9 & 10 \\
\hline Schnittrichtung & $\begin{array}{r}\text { f rontal } \\
\text { horizontal }\end{array}$ & " & $"$ & $"$ & $"$ & " & $"$ & ” & $"$ & $"$ \\
\hline Seite der Serien & $\mathbf{r}$ & 1 & 1 & $\mathbf{r}$ & 1 & $\mathbf{r}$ & 1 & $\mathbf{r}$ & 1 & $\mathbf{r}$ \\
\hline Nr. des For. ac. ant. & 1 & 1 & 1 & 1 & 1 & 1 & 1 & 1 & 1 & 1 \\
\hline Nr. des For. ac. med. & 3 & 4 & 3 & 3 & 2 & $\ddot{2}$ & 2 & 1 & 1 & 1 \\
\hline Nr. des For. ac. post. & 1 & 1 & 1 & 1 & 1 & 1 & 1 & 1 & 1 & 1 \\
\hline Tierarten & -mece & s la & uta & (H & & & & & & Taky- \\
\hline Präparatnummer & 25 & 27 & 29 & 29 & 30 & 31 & 32 & 33 & 34 & 35 \\
\hline Schnittrichtung & $\begin{array}{r}\text { frontal } \\
\text { horizontal }\end{array}$ & $"$ & $"$ & " & " & $"$ & ", & $”$ & $\because$ & $"$ \\
\hline Seite der Serien & $\mathbf{r}$ & 1 & $\mathbf{r}$ & 1 & $\mathbf{r}$ & 1 & $\mathbf{r}$ & 1 & $\mathbf{r}$ & 1 \\
\hline Nr. des For. ac. ant. & 1 & 1 & 1 & 1 & 1 & 1 & 1 & 1 & 1 & 1 \\
\hline Nr. des For. ac. med. & 1 & 1 & 1 & 1 & 1 & 1 & 1 & 1 & & \\
\hline Nr. des For. ac. post. & 1 & 1 & 1 & 1 & 1 & 1 & 1 & 1 & 1 & 1 \\
\hline
\end{tabular}




\section{Zusammenfassung.}

Bei allen ausgewachsenen Tieren von Trionyx japonicus fand ich vier oder mehr Foramina acustica an der medialen Ohrkapselwand und bei Clemmys japonica, Gecko japonicus und Eumeces latiscutatus immer drei derselben; aber beim Takydromus tachdromoides und den Ophidien konnte ich niemals ein Foramen acusticum medium konstatieren, nur ein Foramen anterius und ein Foramen posterius (s. umstehende Tabelle).

Die Foramina acustica liegen hintereinander in der medialen Ohrkapselwand, auf der Grenze zwischen dem oberen grösseren Teil und unteren kleineren Teil der Wand, wie es bei Anuren der Fall ist. Das zwischen dem Foramen anterius und posterius liegende Foramen medium oder Foramina media befindet sich immer auf dem knöchernen Abschnitt des Prooticum.

Bei Trionyx und Clemmys befindet sich das Foramen anterius und medium im Knochen und das Foramen posterius im Knorpel, während bei Gecko und Eumeces latiscutatus alle diese Foramina in Knochenmasse vorhanden sind.

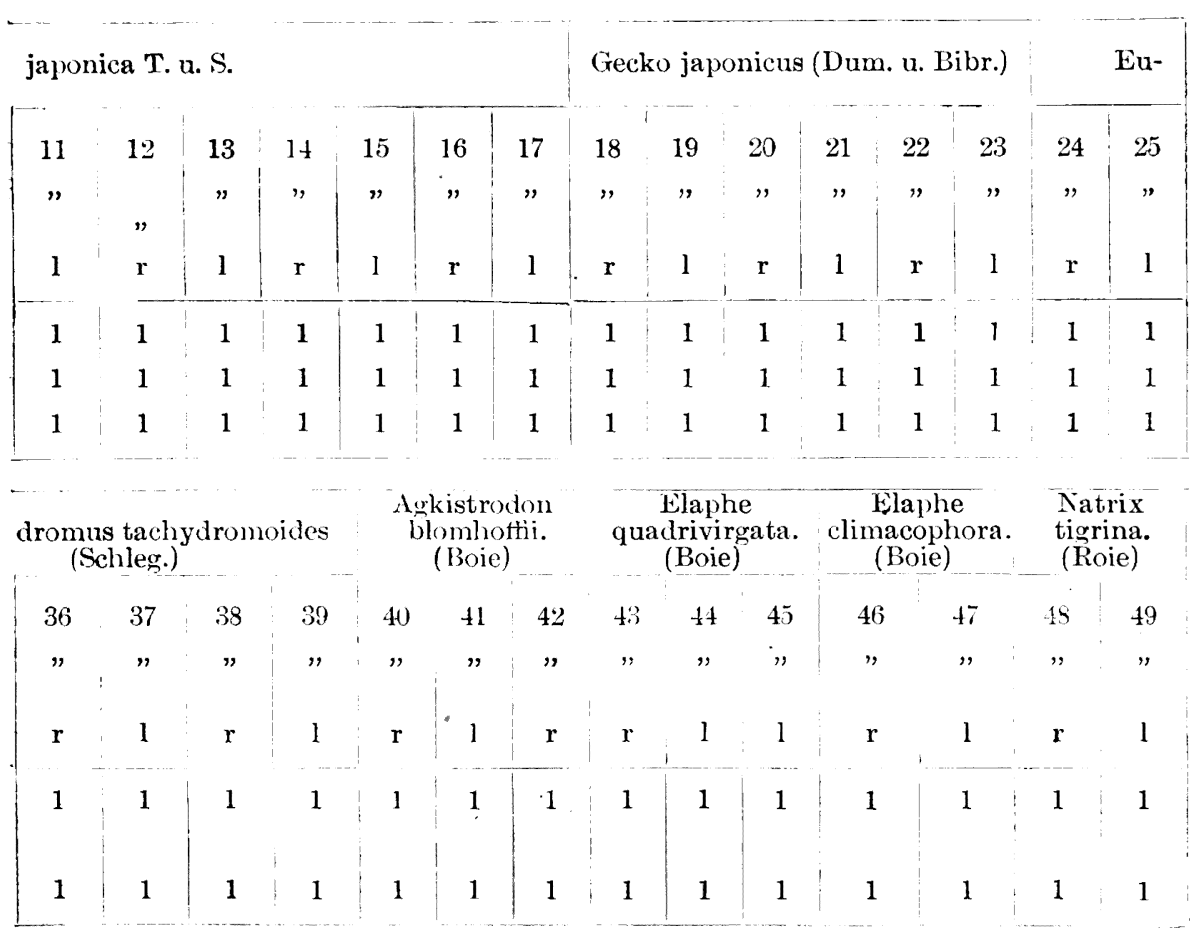


Das Acusticus-Ganglion ist dicht an der medialen Wand gelegen und setzt sich in den Ramus anterior und medius fort. Das Ganglion posterius dehnt sich durch das Forameu acusticum posterius hindurch bis zur Ohrkapselhöhle aus.

Beim Trionyx und Clemmys teilt sich der Ramus anterior in zwei oder mehrere Äste; vor seinem Eintritt in das Foramen anterius gibt er den Ramus medius ab, der durch das Foramen medium hindurch zum Silcculus geht; der andere Ast passiert das Foramen anterius und teilt sich in drei İstchen. Beim Gecko und Eumeces latiscutatus stammt aber der Ramus medius aus dem Ramus posterior: der erstere gelangt nach seinem Austritt aus dem Foramen medium zur Macula sacculi, wïhrend der letztere sich nach seinem Austritt vom Foramen posterius in fünf $Z_{w}$ eige verzweigt.

Der Ramus medius, der durch das Foramen acusticum medium passiert, gelangt bei Urodelen nach Stöhr ('80), Wind ischmann ('18), Retzius ('81) und Okajima ('10) immer zur Macula sacculi; bei Anuren fand ich ('28) aber, dass dieser Nervenzweig zur Lagena geht. Der Ramus medius vom Gecko gelangt zur Macula neglecta nach Hafferl ('21), aber bei allen von mir untersuchten Exemplaren dieses Tieres geht er immer zur Macula sacculi, wie es bei anderen, auch von mir untersuchten Tierarten der Fall ist. Für die Pars neglecta verläift der Ramus neglectus, der kleinste Ast, der rom Ramulus ampullae posterioris sich verzweigt, wie im allgemeinen bekannt ist.

Die Hauptresultate der vorliegenden Arbeit lassen sich folgenderinassen zusammenfassen:

1. Immer sind beim Trionyx japonicus an der medialen Ohrkapselwand zwei oder vier Foramina acustica media und beim Clemmrs, Crecko sowie Eumeces latiscutatus je eins vorhanden. Aber bei allen untersuchten Fällen von Ophidien und Takydromoides ist kein Foramen medium vorzufinden.

2. Beim Trionyx und Clemmys verzweigt sich der Ramus medius, vor seinem Eintritt zum Foramen medium, vom Ramus anterior, während er beim Gecko und Eumeces latiscutatus vom Ramus posterior stammt.

3. Der Ramus medius des Nerrus acusticus endigt nach dem Durchgehen durch das Foramen medium (Foramina media) immer in der Macula sacculi.

Zum Schluss müchte ich Herrn Prof. Dr. K. Okajima für seine dauernde Unterstützung bei dieser Arbeit meinen herzlichsten Dank. aussprechen. 


\section{Literatur.}

1. Fleissig, J., Die Entwickelung des Geckolabyrinthes. Anat. Hefte. Bd. 37. 1908.

2. Gaupp, E., Das Chondrocranium von Lacerta agilis. Win Beitrag zum Verständnis des Amniotenschädels. Anat. Hefte. Bd. 15. 1900.

3. Haff^rl, A., Über das knorpelige Neurocranium des Gecko. Ein Beitrag zur Entıvickelungsgeschichte des Reptilienschädels. Zeitschr. f. Anat. u. Entw. Bd. 62. 1921.

4. Kuhn, Über das häutige Labyrinth der Reptilien. Arch. f. mikr. Anat. Bd. 20. 1882.

5. Kunkel, B. W., Zur Entwickelungs reschichte und vergleichenden Morphologie des Schildkrötenschädels. Anat. Anz. Bd. 39. 1911.

6. Miyawaki, S., Das Vorhandensein des Foramen acusticum medium an der Ohrkapsel von Anuren. Folia anat. japon. Bd. 5. 1927.

7. Nick, L., Das Kopfskelet von Dermochelys coriacea L. Zool. Jahrb. Abt. Anat. Bd. 33. 1912.

8. Ogushi, K., Anatomische Studien an der japanischen dreikralligen Lippenschildkröte (Trionyx japonicus). 1. Mitteilung. Morph. Jahrb. Bd. 43. 1911.

9. Okajima, K., Contribution à l'étude de l'organe de l' ouie chez les Urodèles. Arch. de Biol. Tom. 23. 1910.

10. Osawa, G., Beiträge zur Anatomie der Hatteria punctata. Arch. f. mikr. Anat. Bd. 51. 1898.

11. Retzius, G., Das Gehörorgan der Wirbeltiere. Il. Das Gehörorgan der Reptilien, Vögel u. Säugetiere. Stockholm 1881.

12. Rice, E. L., The development of the skull in the skink, Eumeces quinquelineatus L. 1. The chondrocranium. Journ. Morph. Vol. 34. 1920.

13. Schauinsland, H., Weitere Beiträge zur Entwickelungsgeschichte der Hatteria. Arch. f. mikr. Anat. Bd. 56.1900.

14. Shiino, K., Studien zur Kenntnis des Wirbeltierkopfes. I. Das Chondrocranium von Crocodilus mit Berücksichtigung der Gehirnnerven u. der Kopfgefässe. Anat. Hefte. Bd. 50. 1914.

15. Versluys, J., Die mittlere u. äussere Ohrsphäre der Lacertilia u. Rhynchocephalia. Zool. Jahrb. Bd. 12. 1898.

16. Voit, M., Zur Frage der Verästelung des N. acusticus bei den Säugetieren. Anat. Anz. Bd. 31. 1907.

17. Wiedersheim, R., Vergleichende Anatomie der Wirbeltiere. Leipzig 1898.

18. Zimmermann, Das Chondrocranium von Anguis fragilis. Anat. Anz. Bd. 44. 1913. 